\title{
AVALIAÇÃO DO IMPACTO DA CONCESSÃO DE AEROPORTOS NA SATISFAÇÃO DOS USUÁRIOS QUANTO À INFRAESTRUTURA AEROPORTUÁRIA, ÀS COMPANHIAS AÉREAS, AO TRANSPORTE PÚBLICO E À SATISFAÇÃO GERAL
}

\author{
EVALUATION OF THE IMPACT OF AIRPORT GRANTING ON USER \\ SATISFACTION FOR AIRPORT INFRASTRUCTURE, AIRLINES, \\ PUBLIC TRANSPORT AND GENERAL SATISFACTION
}

Kalina Maria Donato de Araújo Sales ${ }^{1}$ Luiz Honorato da Silva Júnior ${ }^{2}$

Analista de Licitações no Serviço Nacional de Aprendizagem do Cooperativismo, Brasília/DF Mestre em Gestão Pública pela Universidade de Brasília

2

Professor da Universidade de Brasília, Brasília/DF Doutor em Economia pelo PIMES/UFPE
RESUMO: O objetivo deste trabalho é avaliar o impacto da concessão de aeroportos na percepção de satisfação dos passageiros relacionado à infraestrutura aeroportuária, às companhias aéreas, ao transporte público e à satisfação geral dos usuários. A hipótese inicial é que a concessão pública funcionaria como uma forma de tratamento no intuito de melhorar a prestação de serviços. Para viabilizar a referida pesquisa foram criados dois grupos. O grupo de tratamento é composto pelos aeroportos de Natal/RN, Guarulhos/SP, Campinas/SP, Brasília/DF, Confins/MG e Galeão/RJ, enquanto que o grupo de controle é composto pelos aeroportos de Fortaleza/CE, Salvador/BA, Recife/ PE, Porto Alegre/RS, Curitiba/PR, Santos Dumont/RJ, Congonhas/SP, Manaus/ AM e Cuiabá/MT. A partir do método diferenças-em-diferenças, verifica-se que a gestão privada tem se mostrado eficiente no aumento dos indicadores de satisfação dos passageiros quando comparados com os aeroportos não concedidos no mesmo período.

PAlAVRAS-Chave: avaliação de impacto, política pública, concessão de aeroportos.

ABSTRACT: The objective of this work is to evaluate the impact of airport concession in the perception of passenger satisfaction related to airport infrastructure, airlines, public transportation and overall user satisfaction. The initial hypothesis is that the public concession would function as a form of treatment in order to improve the provision of services. To make this research feasible, two groups were created. The treatment group is composed of Natal, Guarulhos, Campinas, Brasília, Confins and Galeão airports, while the control group is composed of Fortaleza, Salvador, Recife, Porto Alegre, Curitiba, Santos Dumont, Congonhas, Manaus and Cuiabá airports. From the differences-in-differences method, private management has been shown to be efficient in increasing passenger satisfaction indicators when compared to airports not granted in the same period.

KEYWORDS: impact evaluation, public policy, airport concession. 


\section{INTRODUÇÃO}

A demanda por transporte aéreo registrou significativo crescimento ao longo das duas últimas décadas no Brasil. De acordo com o Anuário do Transporte Aéreo 2015, divulgado pela Agência Nacional de Aviação Civil (ANAC), a demanda doméstica pelo modal aéreo teve alta de $133 \%$ entre os anos de 2006 e 2015, apresentando crescimento médio de $9,8 \%$ ao ano. O modal aéreo é um elemento de integração do território nacional, apresenta-se como um setor estratégico para o desenvolvimento do país e tem sido o principal meio de transporte utilizado pelos passageiros nas viagens interestaduais com distâncias superiores a 75 quilômetros no Brasil. No ano de 2015 o modal aéreo apresentou $65 \%$ de participação, frente a $35 \%$ do modal rodoviário. (IPEA, 2010; ANAC 2015).

O crescimento ocorrido no setor de transporte aéreo trouxe consigo desafios para a infraestrutura aeroportuária brasileira, evidenciando a necessidade de ampliação dos terminais de passageiros, por exemplo, e investimentos para promover um nível de serviço satisfatório aos usuários. Na concepção de Paiva (2015) o aumento da demanda pelo transporte aéreo ocasionou uma série de problemas, pelo fato da infraestrutura instalada não ter acompanhado a expansão, apontando gargalos no sistema aeroportuário brasileiro.

O país enfrentaria o desafio da realização de grandes eventos mundiais, como a Copa de Mundo FIFA de 2014 e os Jogos Olímpicos Rio 2016. Tal cenário apontou para a urgência nas medidas de adequação da infraestrutura dos aeroportos frente à previsão de maior incremento na demanda de transporte aéreo, como meio de ligação entre as praças de evento e os países envolvidos na competição (IPEA, 2010).

Com a finalidade de modernizar os aeroportos brasileiros e em face da crise fiscal que se avizinhava, a administração pública tratou de executar um plano de concessão de alguns dos principais aeroportos brasileiros. O objetivo era que, por meio da parceria com a iniciativa privada, viabilizasse e acelerasse a realização dos investimentos necessários para a adequação da infraestrutura aeroportuária.

Em agosto de 2011 foi realizado o primeiro leilão para concessão do aeroporto de São Gonçalo do Amarante/RN. Em seguida, outros aeroportos foram leiloados, conforme se descreverá nesse trabalho (ANAC, 2014). A hipótese daqueles que apostam no modelo de concessão/privatização é a de que o setor privado tem maior agilidade e eficiência para promover melhorias e satisfazer o atendimento ao usuário, desde que os incentivos econômicos conduzam-no para a persecução deste fim.

O objetivo deste trabalho é avaliar o impacto da concessão de aeroportos na percepção de satisfação dos passageiros relacionada à infraestrutura aeroportuária, às companhias aéreas, ao transporte público e à satisfação geral dos usuários. 


\section{REFERENCIAL TEÓRICO}

As atividades da aviação civil brasileira tiveram início na década de 20, quando foi realizado o voo inaugural da primeira empresa de aviação no Brasil. Ao longo das décadas subsequentes a demanda pelo transporte aéreo apresentou considerável crescimento, chegando em 2015 a transportar o número recorde de 117,8 milhões de passageiros pagantes (MCKINSEY \& COMPANY, 2010; ANAC, 2015).

Para McKinsey \& Company (2010) o modal aéreo apresenta elevada relevância para a promoção do desenvolvimento e crescimento sustentado de um país com a proporção territorial do Brasil, além de desempenhar o papel de transporte de passageiros e cargas, promove a integração nacional e o estímulo de negócios entre as regiões, fomentando a inserção internacional nos fluxos comerciais e culturais.

O artigo 21 da Constituição da República Federativa do Brasil de 1988 determina como competência da União explorar, diretamente ou mediante autorização, concessão ou permissão: a navegação aérea, aeroespacial e a infraestrutura aeroportuária. Assim, o transporte aéreo é definido como serviço público, devendo ser prestado diretamente pelo Poder Público, passível de monopólio estatal. Todavia, a União tem a prerrogativa de transferir, por meio de autorização, concessão ou permissão a exploração dos aeroportos para a iniciativa privada. (BRASIL, 1988).

O modelo de Administração Aeroportuária concebido inicialmente no Brasil foi concentrado na esfera pública. A infraestrutura aeroportuária ficou sob a responsabilidade administrativa da Empresa Brasileira de Infraestrutura Aeroportuária (Infraero), constituída no ano de 1972, pela Lei oㅜ 5.862. A referida lei dispõe que a Infraero consiste em uma empresa pública, pertencente à União, com personalidade jurídica de direito privado.

Já as atividades de regulação e supervisão da aviação civil e da infraestrutura aeroportuária, atualmente, ficam a cargo da ANAC criada em 2005 pela Lei n.․ำ11.182, para atuar em regime autárquico especial. $\mathrm{O}$ vigoroso crescimento registrado na demanda de transporte aéreo nos últimos anos pode ser atribuído ao gradual processo de liberalização tarifária promovida pela ANAC, que tornou o setor mais dinâmico e competitivo. $\mathrm{O}$ aumento de competitividade ensejou a diminuição do preço e trouxe benefícios aos usuários, que viram o preço médio das passagens baixarem, tornando o avião um transporte mais acessível à população (ANAC, 2015; PAIVA, 2010).

Até o ano de 2011, a Infraero administrava os 67 principais aeroportos do Brasil. Além da demanda crescente para o transporte aéreo, a realização de grandes eventos mundiais no Brasil apontou a necessidade da modernização dos espaços e inovações tecnológicas que promovessem melhorias no atendimento e nos níveis de qualidade dos serviços prestados à sociedade (PAIVA, 2015).

O aparato público que administra o setor de aviação civil passou 
a ter diante de si o desafio de superar obstáculos decorrentes do vigoroso crescimento na demanda do setor ocorrido nas últimas décadas e é sabida a sua dificuldade, algumas vezes, em gerir diretamente com eficiência. Tais dificuldades são, em geral, percebidas na baixa qualidade dos serviços prestados.

São conhecidas as dificuldades que a Infraero encontra em conduzir de maneira satisfatória a gestão direta dos aeroportuários brasileiros. O Comunicado IPEA $\mathrm{n}^{-} 54$ ressalta que a incapacidade da Infraero em acompanhar o ritmo de expansão da demanda por transporte aéreo no país tornou-se notória. $\mathrm{O}$ documento ressalta que a evolução do mercado vem colidindo com obstáculos e gargalos de ordem institucional, legal, infraestrutural e operacional. O estudo aponta que o crescimento acelerado da demanda não foi acompanhado por: adequado planejamento de longo prazo para o sistema de aviação civil; políticas públicas consistentes; marco legal e regulador mais condizente com o novo ambiente competitivo, e; superação das notórias deficiências nas infraestruturas (IPEA, 2010).

O relatório consolidado de McKinsey \& Company (2010) considera que a Infraero expandiu sua capacidade de forma inferior ao que era esperado. O estudo identificou problemas e oportunidades de melhoria em quatro elementos-chave do modelo de administração aeroportuária brasileira: expansão de capacidade, utilização da capacidade existente, sistema de gestão e nível de serviços e tarifas. O estudo apontou para a existência de uma degradação no nível de serviço nos principais aeroportos do Brasil, relacionada à dificuldade de finalização de obras necessárias para expansão e à baixa eficiência operacional.

Já Salgado (2009) considera que a Infraero não possuía planejamento estratégico de longo prazo quanto à expansão e eficiência no uso da infraestrutura aeroportuária, trazendo como consequência urgentes mudanças de gestão.

Também nesse sentido, Paiva (2015) aponta que as dificuldades existentes na infraestrutura aeroportuária não trazem transtornos apenas à indústria da aviação. Os problemas no setor aéreo produzem impactos negativos na sociedade, onde os indivíduos tem seu processo de deslocamento comprometido; e em setores econômicos, como serviços e indústria que dependem do transporte de passageiros e cargas realizados por intermédio do modal aéreo.

Abordando os problemas relativos ao congestionamento nos aeroportos, Ueda (2012) ressalta que o crescimento monotônico da demanda por transporte aéreo torna necessária a criação e ou aperfeiçoamento de instrumentos que adequem a capacidade dos aeroportos frente à demanda. $\mathrm{O}$ autor ressalta que a expansão da infraestrutura aeroportuária é considerada a alternativa mais segura e efetiva para resolver o problema.

Ainda corroborando com o diagnóstico para o setor aeroportuário, o comitê organizador da Copa do Mundo FIFA de 2014, declarou que os aeroportos foram identificados como o grande problema para a 
realização do evento no Brasil (CONMENBOL, 2017). Esse talvez tenha sido o repuxão necessário para que o país se posicionasse de maneira proativa frente aos problemas de infraestrutura aeroportuários já outrora identificados.

\section{CONCESSÃO DE AEROPORTOS NO BRASIL}

A partir do ano de 2011, a política pública adotada pelo Governo Federal foi a concessões de alguns aeroportos federais, como ação necessária ao enfrentamento das dificuldades existentes na gestão aeroportuária, envolvendo a participação da iniciativa privada nos investimentos demandados pelo setor. Nesse sentido, a exploração da iniciativa privada apresenta como vantagens o maior dinamismo na tomada de decisões e na consecução dos investimentos.

Uma decisão como essa que pode ser encarada como trivial e óbvia em ambientes de negócios, pode também ser uma decisão difícil de ser encarada quando envolve crenças em modelos de condução econômica centrada no estatismo.

Alguns autores apontaram para vantagens nas concessões de aeroportos. Justen Filho (2003), por exemplo, define a concessão como um instrumento de implantação de políticas públicas. Para o autor, a concessão não é pura e simplesmente uma manifestação da atividade administrativa contratual da região, mais do que isso, configura-se como uma ferramenta de gestão para realização de valores constitucionais fundamentais.

Consoante o entendimento de Grotti (2011) a vantagem da concessão está no fato de que a União mantém o seu poder de controle sobre o concessionário, inclusive na fixação de preços e pode prestar serviços públicos sem necessitar investir grandes capitais públicos. Importa destacar ainda que a concessão difere da privatização, pois nela não ocorre a venda dos bens e a transferência definitiva da atividade econômica para o ente privado.

Desde o início do programa de concessão de aeroportos federais seis aeroportos foram concedidos à iniciativa privada. $\mathrm{O}$ primeiro foi o aeroporto de São Gonçalo do Amarante, no Rio Grande do Norte, concedido no ano de 2011. Em fevereiro de 2012, o governo federal concedeu o terminal de Brasília, no Distrito Federal e os terminais de Guarulhos e Campinas, na região de São Paulo.

Em dezembro de 2012, o governo federal lançou o Programa de Investimentos em Logística: Aeroportos, que contemplava entre as medidas previstas a concessão dos aeroportos de Galeão, na região do Rio de Janeiro e o de Confins, localizado em Minas Gerais. Em complemento, no ano de 2013, por meio do Decreto $n^{0}$ 7.896, foi incluída ao Processo Nacional de Desestatização a concessão dos aeroportos Galeão/RJ e Confins/MG (BRASIL, 2013).

A modalidade licitatória utilizada para a concessão dos aeroportos foi o leilão previsto na Lei $n^{0}$ 8.666/93, em seu Art. 22. O texto 
da referida Lei define o leilão como a modalidade de licitação entre quaisquer interessados para a venda de bens móveis inservíveis para a administração ou de produtos legalmente apreendidos ou penhorados, ou para a alienação de bens imóveis, a quem oferecer o maior lance, igual ou superior ao valor da avaliação (BRASIL, 1993).

Os leilões ocorridos para concessão da gestão da infraestrutura aeroportuária brasileira tiveram participação de consórcios internacionais na composição dos capitais acionários vencedores do certame. O maior ágio foi oferecido para o aeroporto de Brasília, onde o lance vencedor foi $673,37 \%$ maior do que o valor da outorga mínima para a concessão. O menor ágio foi oferecido no aeroporto de Confins/MG, com valor $66 \%$ acima da outorga mínima definida. Após a assinatura do contrato de concessão houve um período de transição no qual a administração desses terminais foi realizada em conjunto pela Infraero e pela concessionária.

Depois desse período as concessionárias assumiram integralmente as operações de seus respectivos aeroportos. Essa informação se faz importante, porque é muito provável que a percepção de mudanças somente devem ter acontecido posteriormente a esse período de transição.

Importa ressaltar que o leilão para concessão do quarto lote de aeroportos ocorreu em Março de 2017, ocasião na qual foram leiloados os aeroportos de Fortaleza/CE, Salvador/BA, Florianópolis/SC e Porto Alegre/RS. O consórcio Fraport AG Frankfurt Airpor Services foi vencedor dos aeroportos de Fortaleza/CE e Porto Alegre/RS, com ágios de $17,98 \%$ de $852 \%$, respectivamente, em relação à oferta mínima. $\mathrm{O}$ aeroporto de Salvador/BA foi arrematado pelo consórcio Vinci Airport, que ofereceu ágio de $113,25 \%$. O vencedor do leilão para concessão do aeroporto de Florianópolis/SC foi o consórcio Zurich, com ágio de $58,02 \%$ em relação à oferta (Secretaria Nacional de Aviação Civil, 2017). Esses aeroportos não serão objetos de análise deste estudo, pelo caráter recente de suas concessões não apresentar reflexos no período considerado na coleta de dados.

De acordo com a análise de Paiva (2015) a concessão de aeroportos no Brasil consiste em um tema ainda pouco estudado, devido ao caráter recente do processo. Marcos e Ferreira (2015) apontam que o assunto gestão aeroportuária precisa ser tratado com grande prioridade, tanto pelos gestores públicos, como pela academia. Para contribuir com a diminuição dessa lacuna, reveste-se de importância aferir os resultados produzidos pela política pública de concessão nos indicadores de satisfação dos usuários do transporte aeroportuário brasileiro.

\section{AVALIAÇÃO DE IMPACTO DE POLÍTICAS PÚBLICAS}

Conhecida a trajetória percorrida para a concessão de alguns dos maiores aeroportos brasileiros, cabe referenciar a metodologia utilizada na avaliação do impacto na satisfação dos usuários, após a transição da administração para as respectivas concessionárias, ocorrida 
nos aeroportos de Natal/RN, Brasília/DF, Guarulhos/SP, Campinas/SP, Confins/MG e Galeão/RJ.

De acordo com Silva (1999), o interesse na avaliação de atividades de governo teria como motivo mais imediato à preocupação com a efetividade, ou seja, com a aferição dos resultados esperados e não esperados alcançados pela implementação dos programas.

Já na concepção de Frey (2000), avaliar uma política trata de questionar os déficits de impacto, bem como os efeitos colaterais indesejados, tendo por objetivo deduzir consequências para ações e programas futuros.

Trevisan e Bellen (2008) apontam que a avaliação é a fase na qual se aprecia programas já implementados no que diz respeito aos seus impactos efetivos.

Deve-se ressaltar ainda que proceder a uma avaliação de impacto é sempre um grande desafio em função das dificuldades impostas. Tais desafios perpassam pela definição das hipóteses - que em algumas situações precisam ser bastante simplificadoras -, ou na obtenção de dados confiáveis para o procedimento - que em algumas situações se recorre excessivamente a proxies que podem desfigurar o referido efeito. Entretanto, a tarefa de avaliar é sempre necessária e intrépida para que se avance na eficiência das decisões sociais.

\section{MÉTODO E BASE DE DADOS UTILIZADOS}

O tratamento definido para este estudo, conforme discorrido anteriormente, é a concessão da administração dos aeroportos para a iniciativa privada. Os aeroportos concedidos são os de Natal/RN, Guarulhos/SP, Campinas/SP, Brasília/DF, Confins/MG e do Galeão/RJ; os aeroportos não concedidos no mesmo período, considerado grupo de controle, são Fortaleza/CE, Salvador/BA, Recife/PE, Porto Alegre/ PA, Curitiba/PR, Santos Dumont (Rio de Janeiro/RJ), Congonhas (São Paulo/SP), Manaus/AM e Cuiabá/MT - esses são os quinze maiores aeroportos brasileiros e onde é feita uma pesquisa de satisfação (Secretaria de Aviação Civil, 2016).

Nesse contexto, uma avaliação de impacto significa uma variação selecionando uma variável de interesse, Yi, que capte o efeito de uma intervenção. Usualmente, essa intervenção é denominada na literatura como tratamento, pela prevalência desse tipo de estudo na área médica. O ponto fundamental em uma avaliação de impacto é a atribuição do efeito causado unicamente pelo tratamento, pela inferência de uma conexão causal entre a variável de interesse e o tratamento. (CAMERON \& TRIVEDI, 2005; WOOLDRIDGE, 2002).

O outro grupo, aqueles que não são tratados pela política pública é o grupo de controle. Fazem-se necessários que ambos os grupos sejam idênticos. A assunção e validação desta hipótese permite considerar o grupo de controle com um contra factual dos tratados podendo projetar os mesmos resultados observados no tratamento do primeiro 
grupo como sendo àqueles esperados no caso de se tratar o grupo de controle.

Assim, os dois grupos em questão são caracterizados pela participação e não participação na política pública. O grupo que participa da política, e, portanto foi afetado por ela, é chamado de grupo de tratamento, já o grupo que não participou é chamado de grupo de controle. Contextualizando com o objeto deste estudo, para o grupo de tratamento serão considerados os aeroportos concedidos, e para grupo de controle serão considerados os aeroportos não concedidos no mesmo período.

É possível isolar o efeito da política pública que está sendo avaliada considerando que as alterações que aconteceram no grupo de controle, geradas por outros fatores, também poderiam estar afetando o grupo de tratamento, o que é feito ao se calcular a diferença nos valores médios das variáveis de interesse entre os dois grupos (MENEGUIN, 2013).

O período do tratamento foi definido como iniciado a partir do mês de Julho de 2014, tendo em vista que a realização da Copa do Mundo FIFA 2014 no Brasil ensejou para esse período o pleno funcionamento dos aeroportos das doze cidades-sede, a saber: Rio de Janeiro/ RJ, São Paulo/SP, Belo Horizonte/MG, Brasília/DF, Porto Alegre/RS, Curitiba/PR, Fortaleza/CE, Salvador/BA, Recife/PE, Natal/RN, Cuiabá/ MT e Manaus/AM. Apesar das concessões terem o início de sua eficácia em datas diferentes para os aeroportos concedidos, o mês de Julho de 2014 foi o período no qual as obras, investimentos e adequações de infraestrutura deveriam estar concluídos para possibilitar o deslocamento no modal aéreo de pessoas e cargas relacionadas ao Mundial.

A base de dados utilizada foi obtida junto a Secretaria de Aviação Civil. A pesquisa é realizada entre os quinze maiores aeroportos brasileiros. A Figura 1 apresenta o número de passageiros embarcados nos aeroportos que integram esta pesquisa no ano de 2016. 
FIGURA 1 - Número de passageiros embarcados nos aeroportos que integram esta pesquisa, ano de 2016

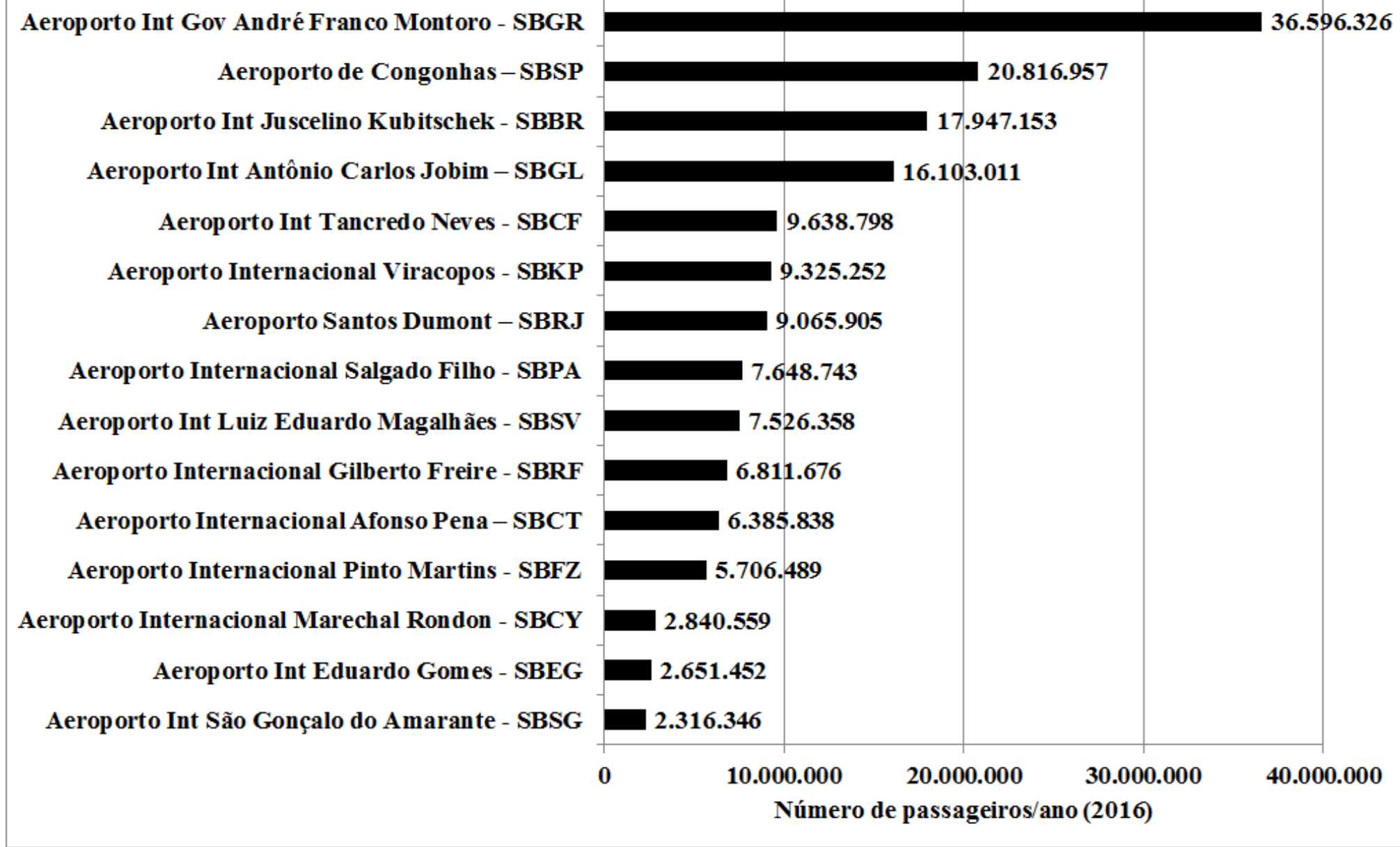

FONTE: Elaboração Própria dos Autores. 
A pesquisa foi realizada do primeiro trimestre do ano de 2013 ao quarto trimestre do ano de 2016. A aplicação do questionário tinha por finalidade aferir o nível de serviço prestado à sociedade, por meio de indicadores de percepção de satisfação dos passageiros.

De acordo com a descrição da metodologia utilizada na pesquisa de satisfação, a coleta de dados é realizada em entrevista presencial, por meio de questionário padrão, no embarque e desembarque de passageiros. As entrevistas são realizadas nos horários de maior fluxo nos aeroportos, visando obter a opinião dos passageiros no momento de maior concentração de atividades operacionais. O passageiro entrevistado avalia indicadores atribuindo notas de um a cinco para cada um deles, sendo um a menor nota possível e cinco a maior nota possível (CONAERO, 2017).

Os dados foram obtidos em consulta a dezesseis Relatórios de Desempenho Operacional dos Aeroportos, onde foram coletados os resultados das pesquisas trimestrais realizada nos anos de 2013, 2014, 2015 e 2016 (CONAERO, 2017). Os indicadores utilizados neste estudo para compor as variáveis são aqueles que foram avaliados regularmente em todos os períodos da pesquisa de satisfação, conforme descrito a seguir:

\section{INFRAESTRUTURA AEROPORTUÁRIA}

Facilidade de desembarque no meio-fio;

Tempo de fila na inspeção de segurança;

Confiabilidade da inspeção de segurança;

Cordialidade e prestatividade dos funcionários da inspeção de segurança;

Disponibilidade e qualidade das informações nos painéis de voo;

Qualidade da internet/wi-fi disponibilizada pelo aeroporto;

Disponibilidade de sanitários;

Limpeza dos sanitários;

Sensação de segurança nas áreas públicas do aeroporto;

Limpeza geral do aeroporto;

Conforto térmico do aeroporto;

Conforto acústico do aeroporto. 


\section{FACILIDADES AO PASSAGEIRO}

Qualidade de instalações de estacionamento de veículos;

Custo-benefício do estacionamento;

Quantidade e qualidade de lanchonetes e restaurantes;

Disponibilidade e localização de caixas eletrônicos/ casas de câmbio/ bancos;

Quantidade e qualidade de estabelecimentos comerciais;

Custo-benefício dos produtos comerciais.

\section{COMPANHIAS AÉREAS}

Tempo de fila no check-in (autoatendimento);

Tempo de fila no check-in (balcão);

Qualidade e prestatividade dos funcionários do check-in;

Qualidade da informação prestada pela companhia aérea;

Velocidade de restituição de bagagem;

Integridade da bagagem.

\section{TRANSPORTE PÚBLICO}

Disponibilidade de transporte público para o aeroporto.

\section{SATISFAÇÃO GERAL}

É sabido que não é o ideal estimar impacto de políticas públicas a partir da percepção do usuário uma vez que tal indicador pode variar entre usuários que podem ser mais ou menos exigente. Entretanto, para este tipo de política pública não parece existir indicador melhor uma vez que não há outro que revele diretamente os efeitos do tratamento.

\section{ESTIMAÇÃO POR DADOS EM PAINEL COM EFEITO FIXO}

O modelo utilizado pode ser definido da seguinte forma: seja $Y_{\text {rist }}$ o resultado de interesse do aeroporto $i$, para a região s no tempo $t$; dado que o aeroporto passou pelo processo de concessão; $\mathrm{Y}_{\text {oist }} \mathrm{o}$ resultado de interesse do aeroporto $\mathrm{i}$, a região s no tempo t; caso o aeroporto não tivesse passado pelo processo de concessão; $T_{i}$ a variável binária que indica o status de tratamento do aeroporto. $T_{i}=1$, para os aeroportos que foram concedidos à iniciativa privada e $\mathrm{T}_{\mathrm{i}}=\mathrm{O}$, para os aeroportos que compões o grupo de controle e que não foram concedidos no mesmo período.

Para adoção do método diferença-em-diferenças será realizada uma regressão com dados em painel. Para cada aeroporto analisado, no método diferença-em-diferenças com dezesseis períodos, são coletados dados nos períodos anteriores e posteriores à concessão. A partir disso, será estimada uma regressão linear por Mínimos Quadrados Ordinários (MQO) para dados em painel com efeitos fixos nos aeroportos. O método de avaliação deste trabalho segue como orientador o trabalho de Silva Júnior, Pedrosa e Silva (2013). 
No uso do método diferença-em-diferenças há o pressuposto de que os efeitos dos fatores não observáveis que influenciam as variáveis de resultado permanecem constantes no tempo. A partir da suposição de que o efeito do tratamento é aditivo, tem-se que uma função linear seria capaz de capturar o efeito real. O comportamento das variáveis de interesse pode ser expresso na equação abaixo:

$$
Y_{\text {ist }}=\alpha+\theta_{i}+\gamma_{\mathrm{ti}}+\beta_{\mathrm{II}}+\delta X_{\mathrm{it}}+u_{\mathrm{it}}
$$

Onde,

$$
\begin{aligned}
& \alpha \text { é o termo de intercepto; }
\end{aligned}
$$

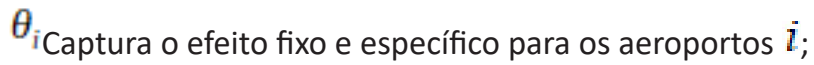

$$
\begin{aligned}
& Y_{t i} \cdot \text { É o coeficiente que mede o efeito da dummy de tempo; } \\
& \beta_{\pi} \text { "Captura o impacto da política pública sobre a variável de interesse; } \\
& \text { IIÉ uma variável dummy que identifica se o aeroporto foi ou não foi } \\
& \text { tratado; }
\end{aligned}
$$

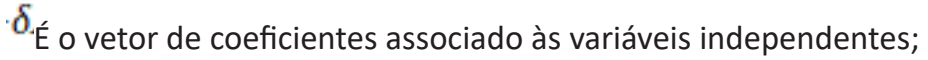

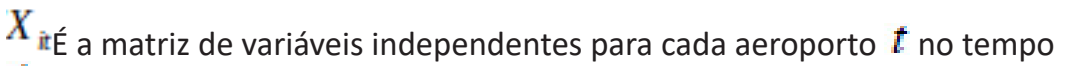

$$
\begin{aligned}
& t
\end{aligned}
$$

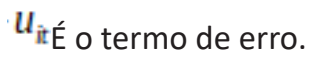

Com relação às regiões foram consideradas as cinco macrorregiões brasileiras, a saber: Norte, Nordeste, Sudeste, Sul e Centro-Oeste, sendo esta última a variável dummy de comparação. O objetivo destas variáveis é o de controlar os efeitos regionais que podem influenciar a percepção de satisfação dos respondentes uma vez que os usuários dessas diversas regiões podem ter exigências diferenciadas.

Com relação às variáveis independentes para cada aeroporto o modelo incorporou as variáveis: "Passageiros", "Voos" e "Passageiros/ Voo". A primeira guarda relação com a densidade de passageiros uma vez que aeroportos com maior trânsito de passageiros podem guardar uma relação direta com insatisfação dos usuários em relação aos serviços, fazendo com que os maiores aeroportos apresentem menor satisfação em função dessa característica. A segunda variável, ao contrário da primeira, pode ter uma relação positiva isoladamente, uma vez que uma maior oferta de voos pode elevar a satisfação. A terceira relação tem a ver diretamente com a qualidade dos serviços uma vez que pode revelar voos com maior lotação e a consequente relação com a percepção de satisfação.

Para Wooldridge (2002), uma grande vantagem desse método é que os dados de painel permitem que se estimem consistentemente efeitos de tratamento sem a suposição de ignorabilidade do tratamento e sem uma variável instrumental; fornece respostas do tratamento variando sobre o tempo e é não correlacionado com variáveis não observáveis que variam no tempo e que afetam a resposta. 


\section{RESULTADOS}

Os resultados obtidos neste estudo apontam que houve melhora na satisfação dos passageiros em todos os aeroportos brasileiros que participam da pesquisa realizada pela SAC, porém, os aeroportos tratados foram mais bem avaliados do que os que não foram tratados no mesmo período. A Figura 2 apresenta a média e mediana dos aeroportos tratados e dos não tratados no período concernente ao primeiro trimestre de 2013 até o final do ano de 2016.

Figura 2 - Nível médio de satisfação geral dos grupos de tratamento e controle concernente ao período de janeiro de 2013 a outubro de 2016

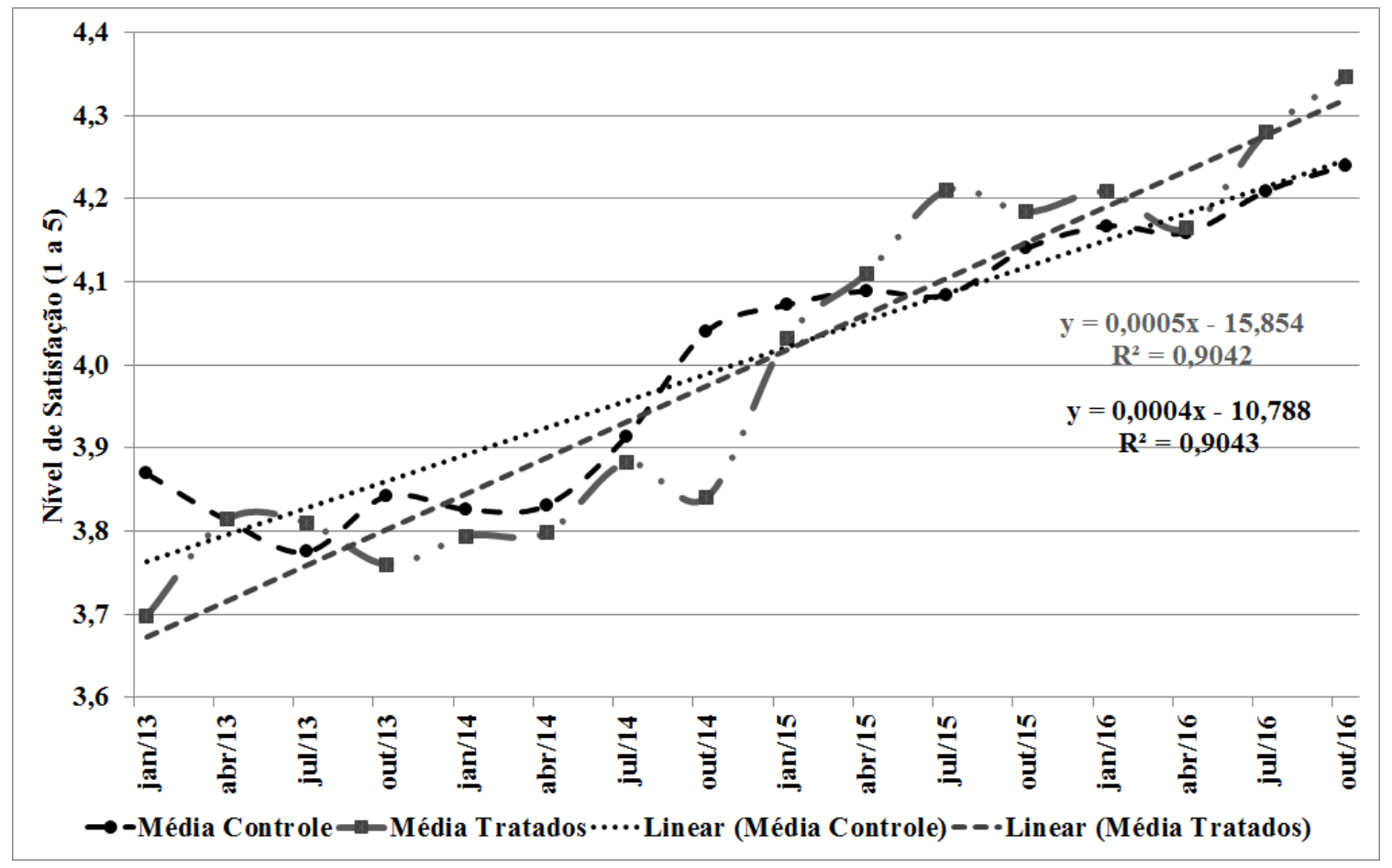

FONTE: Elaboração Própria dos Autores. 
Conforme se verifica na Figura 2, há uma tendência de crescimento na percepção de satisfação geral. A média do grupo de tratados inicia a trajetória no início de 2013 em torno de 3,7 e chega ao final do ano de 2016 em torno de 4,3. Por outro lado, o grupo de controle inicia a série com média equivalente a quase $3,9 \mathrm{e}$ encerra o período com um valor um pouco superior a 4,2. Conforme se verifica há uma tendência de crescimento maior das médias de percepção do grupo de tratamento em relação ao grupo de controle, conforme se verifica nas funções denominadas: "Linear". Esse é um resultado interessante uma vez que mostra que os aeroportos que foram concedidos não eram os melhores avaliados pelos usuários, mas encerram a série com uma avaliação média superior ao grupo de controle.

A Figura 2, entretanto, é meramente ilustrativa - apesar de importante. Não se tem ali, por exemplo, um teste estatístico de diferença de média para que se tenha maior concretude a respeito da robustez do resultado. Não tem ainda um mecanismo de controle para que se ponderem as características dos dois grupos evitando que se mascarem eventualmente os resultados.

Em seguida, são apresentados quatro modelos de regressões em dados de painel com efeito fixo com a finalidade de se estimar o efeito de tratamento dessa política aeroportuária.

O primeiro modelo refere-se a um modelo de Satisfação Geral onde, como o próprio nome do modelo aponta, foi considerada a percepção de satisfação geral dos passageiros com a utilização dos serviços prestados pelos aeroportos pesquisados.

O segundo modelo trata-se do modelo denominado de Infraestrutura Aeroportuária que visa captar o efeito da satisfação dos usuários com os indicadores relacionados à qualidade da infraestrutura física oferecida pelos aeroportos.

O terceiro é o modelo denominado Companhias Aéreas que visa verificar a percepção de satisfação com a qualidade dos serviços prestados pelas companhias aéreas que executam a operacionalização dos voos nos aeroportos pesquisados.

E, por fim, o quarto e último modelo, refere-se ao modelo Transporte Público que visa captar a percepção da satisfação com a qualidade oferecida com o transporte público que dá acesso aos aeroportos pesquisados.

Os resultados obtidos para os quatro modelos são os apresentados na Tabela 1 que traz as análises de Regressão da Concessão na Satisfação dos Passageiros. 
TABELA 1 - Análise de Regressão da Concessão na Satisfação dos Passageiros

\begin{tabular}{|c|c|c|c|c|}
\hline Variáveis/Modelos & $\begin{array}{c}\text { Satisfação } \\
\text { Geral }\end{array}$ & $\begin{array}{l}\text { Infraestrutura } \\
\text { Aeroportuária }\end{array}$ & $\begin{array}{c}\text { Companhias } \\
\text { Aéreas }\end{array}$ & $\begin{array}{l}\text { Transporte } \\
\text { Público }\end{array}$ \\
\hline $\begin{array}{l}\text { Efeito de } \\
\text { Tratamento }\end{array}$ & $\begin{array}{l}0,148^{* * *} \\
(0,042) \\
\end{array}$ & $\begin{array}{c}0,241^{* * *} \\
(0,037) \\
\end{array}$ & $\begin{array}{r}0,052 \\
(0,041) \\
\end{array}$ & $\begin{array}{r}0,206^{* *} \\
(0,081) \\
\end{array}$ \\
\hline Passageiros & $\begin{array}{r}-5,737 \mathrm{E}-8^{* * *} \\
(0,000) \\
\end{array}$ & $\begin{array}{r}-8,834 \mathrm{E}-8^{* * *}, \\
(0,000) \\
\end{array}$ & $\begin{array}{r}-9,020 \mathrm{E}-8^{* * *} \\
(0,000) \\
\end{array}$ & $\begin{array}{r}-9258 \mathrm{E}-8^{* *} \\
(0,000) \\
\end{array}$ \\
\hline Voos & $\begin{array}{r}5,243 \mathrm{E}-6^{* * *} \\
(0,000)\end{array}$ & $\begin{array}{r}6,582 \mathrm{E}-6^{* * *} \\
(0,000) \\
\end{array}$ & $\begin{array}{r}3,360 \mathrm{E}-6^{*} \\
(0,000)\end{array}$ & $\begin{array}{r}-5,343 \mathrm{E}-6 \\
(0,000) \\
\end{array}$ \\
\hline Passageiros/Voo & $\begin{array}{l}0,002^{\text {*** }} \\
(0,001)\end{array}$ & $\begin{array}{r}0,002^{* *} \\
(0,001) \\
\end{array}$ & $\begin{array}{r}0,002^{* *} \\
(0,001) \\
\end{array}$ & $\begin{array}{r}0,002 \\
(0,001) \\
\end{array}$ \\
\hline Norte & $\begin{array}{l}0,259^{* * *} \\
(0,072)\end{array}$ & $\begin{array}{l}0,145^{* *} \\
(0,063)\end{array}$ & $\begin{array}{r}-0,220^{* * *} \\
(0,070) \\
\end{array}$ & $\begin{array}{r}0,205 \\
(0,140) \\
\end{array}$ \\
\hline Nordeste & $\begin{array}{l}0,358^{* * *} \\
(0,055)\end{array}$ & $\begin{array}{l}0,253^{* * *} \\
(0,048)\end{array}$ & $\begin{array}{r}0,010 \\
(0,053) \\
\end{array}$ & $\begin{array}{l}0,280^{* * *} \\
(0,106) \\
\end{array}$ \\
\hline Sudeste & $\begin{array}{l}0,295^{* * *} \\
(0,048)\end{array}$ & $\begin{array}{l}0,262^{* * *} \\
(0,042)\end{array}$ & $\begin{array}{l}0,119^{* *} \\
(0,046)\end{array}$ & $\begin{array}{l}0,726^{* * *} \\
(0,093) \\
\end{array}$ \\
\hline Sul & $\begin{array}{l}0,539^{* * *} \\
(0,060)\end{array}$ & $\begin{array}{l}0,417^{* * *} \\
(0,053)\end{array}$ & $\begin{array}{l}0,168^{* * *} \\
(0,058)\end{array}$ & $\begin{array}{l}0,866^{* * *} \\
(0,117) \\
\end{array}$ \\
\hline Dummies de tempo & Sim & Sim & Sim & Sim \\
\hline $\mathbf{R}^{2}$ & 0,547 & 0,465 & 0,420 & 0,530 \\
\hline $\begin{array}{l}\text { F } \\
\text { (sig.) }\end{array}$ & $\begin{array}{l}11,320 \\
(0,000) \\
\end{array}$ & $\begin{array}{r}8,170 \\
(0,000) \\
\end{array}$ & $\begin{array}{r}6,806 \\
(0,000) \\
\end{array}$ & $\begin{array}{l}10,585 \\
(0,000) \\
\end{array}$ \\
\hline Durbin-Watson & 2,072 & 2,074 & 2,078 & 1,986 \\
\hline
\end{tabular}

FONTE: Elaboração Própria dos Autores.

NOTA: Erro padrão entre parênteses com $\mathrm{p}>0,10=*, p>0,05=* *$ e $p>0,01=* * *$

Na referida tabela são apresentados os estimadores, o desvio padrão do estimador, assim como, o nível de significância desses estimadores. Além disso, cada modelo apresenta ainda os valores das estatísticas de $\mathrm{R}$ ao quadrado, teste $\mathrm{F}$ e o teste de Durbin-Watson. É importante ressaltar ainda que todos os modelos apresentados tiveram variáveis de dummy de tempo como controle, visando captar efeitos temporais de variáveis não observadas que poderiam afetar os resultados. Os resultados obtidos para o efeito do tratamento apontam que houve melhor avaliação dos passageiros nos ae- 
roportos tratados em relação à "Satisfação Geral", à "Infraestrutura Aeroportuária" e ao "Transporte Público". O modelo "Companhias Aéreas" apresentou impacto positivo, entretanto, não significativo estatisticamente. Porém, percebe-se que o impacto da concessão aeroportuária ocorreu de maneira distinta em cada um dos modelos.

No que se refere ao efeito do tratamento, o maior impacto ocorreu na satisfação dos passageiros em relação à Infraestrutura Aeroportuária. Os resultados apontam que os aeroportos tratados tiveram uma percepção de satisfação o,241 maior que os aeroportos do grupo de controle, em um indicador que varia de um a cinco, conforme detalhado anteriormente. Esse resultado traz consigo evidências de que o usuário percebe melhores serviços relacionados à facilidade de desembarque no meio-fio; tempo de fila na inspeção de segurança; confiabilidade da inspeção de segurança; cordialidade e prestatividade dos funcionários da inspeção de segurança; disponibilidade e qualidade das informações nos painéis de voo; qualidade da internet/wi-fi disponibilizada pelo aeroporto; disponibilidade de sanitários; limpeza dos sanitários; sensação de segurança nas áreas públicas do aeroporto; limpeza geral do aeroporto; e, conforto térmico do aeroporto; conforto acústico do aeroporto que são os itens avaliados em infraestrutura. É importante ressaltar que os resultados mostram que a percepção melhorou no todo, podendo haver percepção de piora ou estabilidade em alguns desses itens isoladamente.

Também houve impacto positivo e estatisticamente significante na percepção de satisfação dos passageiros em relação ao Transporte Público. Nesse caso, o item a ser avaliado, referia-se a disponibilidade de transporte público para o aeroporto.

Houve também impacto relevante e estatisticamente significante relacionado à Satisfação Geral. Assim, pode-se afirmar que há uma percepção de melhorias de aumento de bem estar. De maneira mais ampla os usuários avaliaram melhor aqueles aeroportos que passaram a ser concedidos ao capital privado para administrá-los e tais resultados trazem evidências de que parcerias entre o poder público e o setor privado podem trazer ganhos de satisfação neste setor.

Não se pode descartar aqui o efeito instrumentos que altere a percepção do usuário, por exemplo, o efeito do marketing e da propaganda. Sabe-se que o setor privado pode ser mais eficiente também na difusão de seus produtos e benefícios. Contudo não se podem decompor os resultados nem mesmo afirmar que haja efeito de difusão.

Por outro lado, na análise do modelo relacionado às Companhias Aéreas, não se verificou impacto estatisticamente significante. O curioso é que nesse aspecto, ao longo do processo de levantamento e análise de dados, foi possível observar que o item mais bem avaliado em todos os aeroportos na satisfação dos usuários era o serviço prestado pelas companhias aéreas, antes mesmo das concessões. Sendo assim, verifica-se que a concessão não parece ter resultado em mudanças significativas para os indicadores relacionados à prestação de serviço das 
companhias aéreas, que já possuíam uma boa avaliação de satisfação.

Com relação às variáveis de controle, verifica-se uma rígida regularidade. A variável "Passageiros" indica que aeroportos com maior número de passageiros tendem a enfrentar piores indicadores de satisfação, como se poderia esperar. Esse é um resultado esperado, entretanto, os trabalhos de pesquisa brasileiros não tem se atido a relacionar tal variável com a satisfação dos passageiros, como o trabalho de Bandeira et ali (2014).

Em relação a variável "Voos" também se verifica esta mesma regularidade. Aqueles aeroportos com maior oferta de voos tendem a agradar mais os passageiros.

E, por fim, a variável "Passageiros/Voo" também aponta para tal regularidade. É possível imaginar que esses são os fatores mais importantes para os passageiros, enquanto que a qualidade das instalações, tempo de fila na inspeção de segurança, qualidade da internet/wi-fi disponibilizada pelo aeroporto, etc., são apenas acessórios importantes no conforto dos passageiros.

Com relação às regiões em que os aeroportos estão situados, quase todas as regiões nos quatro modelos propostos, observa-se efeito positivo e estatisticamente significante. Há exceção apenas no modelo "Companhias Aéreas" quando os usuários da região Norte inverteram o sinal. Esse resultado pode ser interpretado de duas possíveis maneiras: os serviços dos Aeroportos de Brasília e Cuiabá são significativamente inferiores comparados aos demais Aeroportos estudados ou, os usuários da Capital Federal e da Capital Mato-grossense são mais exigentes e por isso avaliam pior seus serviços. Não se pode afirmar de maneira categórica qual das opções seria mais provável. Tal resultado é consequência da limitação de se avaliar impacto de políticas públicas a partir de percepção do usuário.

\section{CONCLUSÕES}

Os resultados obtidos neste estudo apontam para a efetividade da política pública de concessão para aumentar o nível de satisfação dos usuários com o serviço de transporte aeroportuário. Verificou-se que os recursos arrecadados com os leilões possibilitou o investimento na infraestrutura dos aeroportos localizados nas cidades-sede da Copa do mundo de futebol, tanto nos concedidos, como nos não concedidos. Uma vez que, de maneira geral, todos os aeroportos pesquisados receberam melhorias, resta evidenciada a eficácia da gestão privada na qualidade dos serviços prestados aos passageiros, resultando em uma melhor avaliação nos indicadores de satisfação.

Ressalta-se ainda que os novos leilões ocorridos em Março de 2017 resultaram na concessão de quatro aeroportos brasileiros: Fortaleza/CE, Salvador/BA, Florianópolis/SC e Porto Alegre/RS. Os resultados obtidos por esses aeroportos após a concessão poderão ser considerados contra factuais aos resultados que este estudo obteve. Assim, verifica-se que o campo de estudos relacionado à concessão é 
vasto e pode ser explorado em estudos futuros buscando aprofundar o conhecimento acadêmico relacionado ao tema.

No que se refere ao efeito do tratamento, o maior impacto ocorreu na satisfação dos passageiros em relação à Infraestrutura Aeroportuária, os resultados apontam que os aeroportos tratados tiveram uma percepção de satisfação 0,241 maior que os aeroportos do grupo de controle, em um indicador que varia de um a cinco. Contudo, verificou-se impacto também com relação à percepção dos usuários em relação ao Transporte Público e a Satisfação Geral.

Este estudo pode ser aprofundado incluindo a análise de outros fatores além da percepção de satisfação dos usuários, a exemplo de capacidade operacional de pistas, movimentação de carga, lucro/prejuízo obtido pelas concessionárias, entre outros indicadores que possibilitarão chegar a conclusões mais aprofundadas dos desdobramentos da concessão aeroportuária no Brasil. Contudo, nesta etapa da pesquisa, não foi possível incorporar tais aspectos em função da escassez informacional.

Além disso, e mais importante, este estudo traz evidências de confirmação da hipótese de que o capital privado, por ser mais eficiente em sua aplicação e busca por resultados, pode ser um importante aliado na modernização do setor aeroportuário brasileiro, à luz do que acontece nas principais economias desenvolvidas do mundo. 


\section{REFERÊNCIAS}

ANAC. Dúvidas sobre as concessões? Disponível em http://www.anac.gov.br/noticias/2011/duvidassobre-as-concessoes, acesso em 14/02/2017.

Anuário do Transporte Aéreo 2015 - ANAC. Disponível em: http://www.anac.gov. br /assuntos/dados-eestatisticas/dados-do-anuariodo-transporte-aereo

AGÊNCIA NACIONAL DE AVIAÇÃO CIVIL- ANAC. [Desenvolvido pela ANAC]. 2014. Disponibiliza dados sobre a entidade. Disponível em: <http:// www.anac.gov.br> Acesso em: o5 fev. 2017.

BANDEIRA, Michelle C. G. S. P. et ali. Principais indicadores que afetam a percepção da qualidade de serviço em áreas críticas do embarque de passageiros aeroportuários. Journal of Transport Literature. vol.8 no.4 Manaus Oct. 2014.

BRASIL. Constituição da República Federativa do Brasil, de 5 de outubro de 1988. Disponível em: <http:// www.planalto.gov.br.htm>. Acesso em: 5 fev. 2017.

BRASIL. Lei Federal 8666, de 21 de junho de 1993 - institui normas para licitações e contratos da Administração Pública. Disponível em: <http://www.planalto.gov.br/ ccivil_03/leis/L8666cons.htm>. Acesso em: 05 jan. 2017.

BRASIL. Decreto $n^{\circ} 7.896$, de 1 de fevereiro de 2013. Dispõe sobre a inclusão no Programa Nacional de Desestatização - PND do Aeroporto Internacional do Rio de Janeiro/ Galeão - Antonio Carlos Jobim, localizado no Município do Rio de Janeiro, Estado do Rio de Janeiro, e do Aeroporto Internacional Tancredo Neves, localizado nos Municípios de Confins e de Lagoa Santa, Estado de Minas Gerais, e dá outras providências. Diário Oficial da União. Brasília,DF,1fev.2103.Disponívelem: <http://www.planalto.gov. br/ccivil_03/leis/L9491 . htm \#art35>. Acesso em: 10 fev. 2017.

CAMERON, A. Colin \& TRIVEDI, Pravin K. Microeconometrics: Methods and Aplications. New York: Cambridge University Press, 2005.

CONAERO - Comissão Nacional das Autoridades Aeroportuárias. Metodologia de Coleta de Dados de Desempenho Operacional dos Aeroportos. Disponivel em: http://portal.aviacao.gov.br/noticias/2015/o8/passageirosestao-muito-satisfeitos-com-aeroportos-mais-movimentadosdo-brasil/metodologia.pdf. acesso em 26/05/2017. 
CONMENBOL. Airports: the headache of the 2014 World Cup. Disponível em http://www.conmebol.com/en/content/ airports-headache-2014-world-cup, acesso em 27/02/2017.

COSTA, Frederico L. da; CASTANHAR, José C. Avaliação de programas públicos: desafios conceituais e metodológicos. Revista de Administração Pública, Rio de Janeiro, v. 37, n. 5, p. 969-992, set./out. 2003.

FREY, K. Políticas públicas: um debate conceitual e reflexões referentes à prática da análise de políticas públicas no Brasil. Planejamento e Políticas Públicas, Brasília, n. 21, jun. 2000, p.211-259.

GROTTI, Dinorá Adelaide Musetti. A experiência brasileira nas concessões de serviços públicos. In: SUNDFELD, Carlos Ari (Org.). Parcerias públicoprivadas. São Paulo: Malheiros, 2011. p. 180-251.

IPEA. Infraestrutura Econômica no Brasil: diagnósticos e perspectivas para 2025. Brasilia, Livro 6, Volume 1, Cap. 8, 2010.

JUSTEN FILHO, Marçal. Curso de Direito Administrativo. 7. ed. rev. e atual. 1 reimp. Belo Horizonte: Fórum, 2011.

JUSTEN FILHO, Marçal. Teoria geral das concessões de serviço público. São Paulo: Dialética, 2003,p. 58-59.

McKinsey \& Company. Estudo do Setor de Transporte Aéreo do Brasil: Relatório Consolidado. Rio de Janeiro, 2010. Disponível em: <http://www.bndes.gov.br/SiteBNDES/ bndes/bndes_pt/Institucional/Apoio_Financeiro/ Apoio_a_estudos_e_pesquisas/BNDES_FEP/prospeccao/ chamada_aereo.html>Acesso em: 20 fev. 2012.

MARCOS, Antonio Rodolfo Araujo; FERREIRA, Luciano. Um Modelo de Simulação para Gestão da Capacidade dos Aeroportos Brasileiros. Revista Eletrônica de Administração, v. 21, n. 1, p. 1-26.

MENEGUIN, Fernando Boarato; FREITAS, Igor Vilas Boas de. Aplicações em avaliação de políticas públicas: metodologia e estudos de caso. 2013.

NERI, M. C.; Medrado, A.L. "Experimentando Microcrédito: uma Análise de Impacto do CrediAmigo no Acesso a Crédito". Revista Econômica do Nordeste, v. 41, pp. 133- 154.

PAIVA, Izabela Davanzo de. Concessão de Aeroportos no Brasil: a transferência da gestão do Aeroporto de Confins para a iniciativa privada. 2015 (Dissertação Universidade Federal de Alfenas, campus Varginha /MG). 
SALGADO, Lúcia Helena. Caos aéreo e tragédia dos comuns: falhas de mercado e de governo. Brasília, DF: IPEA, 2009. Disponível em:<http://repositorio.ipea.gov. br /handle /11058/1566>. Acesso em: 26 fev. 2017.

SCHOR, A. AFONSO, L. E. Avaliação Econômica de Projetos Sociais. ${ }^{2}$. ed. São Paulo:Fundação Itaú Social, 2007. 52p.

Secretaria Nacional de Aviação Civil. Governo arrecada $R \$ 1,46$ bi com a concessão de quatro aeroportos. Disponível em http://www.aviacao.gov.br/noticias/2017/03/ governo-arrecada-r-1-46-bi-com-a-concessao-dequatro-aeroportos/view, acesso em 16/03/2017.

Satisfação do Passageiro. Disponível em http://www.aviacao. gov.br/assuntos/pesquisa-satisfacao, acesso em 27/02/2016.

SILVA, Pedro L. B. (coord.) Modelo de Avaliação de Programas Sociais Prioritários: relatório final. Programa de Apoio à Gestão Social no Brasil. Campinas, NEPP-UNICAMP, 1999.

SILVA JÚNIOR, Luiz Honorato da; PEDROSA, Beatriz Mesquita Jardim e SILVA, Márcio Francisco da. Avaliação dos impactos do ICMS Socioambiental na criação de unidades de conservação e unidades de tratamento de resíduos sólidos em Pernambuco: uma análise a partir do método de diferenças-em-diferenças. Rev. Econ. NE, Fortaleza, v. 44, n. 2, p. 559-574, abr-jun. 2013.

Trevisan, Andrei Pittol and Van Bellen, Hans Michael. Avaliação de políticas públicas: uma revisão teórica de um campo em construção. Rev. Adm. Pública, Jun 2008, vol.42, no.3, p.529-550.

Ueda, Thiago. Vinicius. A. (2012a) Congestionamento em aeroportos: há alguma saída para o caos? Journal of Transport Literature, Vol. 6, n.2.

WOOLDRIDGE, Jeffrey. Econometric Analysis of Cross Section and Panel Data. Cambridge: MIT Press, 2002. 